\title{
Verteporfin-Loaded Anisotropic Poly(Beta-Amino Ester)-Based Micelles Demonstrate Brain Cancer-Selective Cytotoxicity and Enhanced Pharmacokinetics
}

This article was published in the following Dove Press journal:

International Journal of Nanomedicine

\author{
James G Shamul ${ }^{1,2, *}$ \\ Sagar R Shah ${ }^{1-3, *}$ \\ Jayoung Kim ${ }^{1,2}$ \\ Paula Schiapparelli ${ }^{3}$ \\ Carla A Vazquez-Ramos ${ }^{3}$ \\ Ben J Lee $\mathbb{D}^{1,2}$ \\ Kisha K Patel ${ }^{1,2}$ \\ Alyssa Shin $\mathbb{1 D}^{1,2}$ \\ Alfredo Quinones-Hinojosa ${ }^{3}$ \\ Jordan J Green (1D) 1,2,4-6 \\ 'Department of Biomedical Engineering, \\ Johns Hopkins School of Medicine, \\ Baltimore, MD 2I23I, USA; \\ ${ }^{2}$ Translational Tissue Engineering Center \\ and Institute for NanoBioTechnology, \\ Johns Hopkins School of Medicine, \\ Baltimore, MD 2I23I, USA; \\ ${ }^{3}$ Department of Neurosurgery, Mayo \\ Clinic, Jacksonville, FL 32224, USA; \\ ${ }^{4}$ Department of Neurosurgery, Johns \\ Hopkins Hospital, Baltimore, MD 2I23I, \\ USA; ${ }^{5}$ Department of Oncology, The \\ Sidney Kimmel Comprehensive Cancer, \\ and The Bloomberg Kimmel Institute for \\ Cancer Immunotherapy, Johns Hopkins \\ School of Medicine, Baltimore, MD \\ 2I23I, USA; 'Department of \\ Ophthalmology, Department of Materials \\ Science and Engineering, and Department \\ of Chemical and Biomolecular \\ Engineering, Johns Hopkins University, \\ Baltimore, MD 21231, USA
}

*These authors contributed equally to this work

Correspondence: Alfredo QuinonesHinojosa; Jordan J Green

Email Quinones-Hinojosa.Alfredo

@mayo.edu; green@jhu.edu
Background: Nanomedicine can improve traditional therapies by enhancing the controlled release of drugs at targeted tissues in the body. However, there still exists disease- and therapyspecific barriers that limit the efficacy of such treatments. A major challenge in developing effective therapies for one of the most aggressive brain tumors, glioblastoma (GBM), is affecting brain cancer cells while avoiding damage to the surrounding healthy brain parenchyma. Here, we developed poly(ethylene glycol) (PEG)-poly(beta-amino ester) (PBAE) (PEG-PBAE)-based micelles encapsulating verteporfin (VP) to increase tumor-specific targeting.

Methods: Biodegradable, pH-sensitive micelles of different shapes were synthesized via nanoprecipitation using two different triblock PEG-PBAE-PEG copolymers varying in their relative hydrophobicity. The anti-tumor efficacy of verteporfin loaded in these anisotropic and spherical micelles was evaluated in vitro using patient-derived primary GBM cells.

Results: For anisotropic micelles, uptake efficiency was $\sim 100 \%$ in GBM cells (GBM1A and JHGBM612) while only $46 \%$ in normal human astrocytes (NHA) at $15.6 \mathrm{nM} \mathrm{VP}(\mathrm{p} \leq 0.0001)$. Cell killing of GBM1A and JHGBM612 vs NHA was $52 \%$ and $77 \%$ vs $29 \%$, respectively, at 24 hrs post-treatment of $125 \mathrm{nM}$ VP-encapsulated in anisotropic micelles $(\mathrm{p} \leq 0.0001)$, demonstrating the tumor cell-specific selectivity of VP. Moreover, anisotropic micelles showed an approximately fivefold longer half-life in blood circulation than the analogous spherical micelles in a GBM xenograft model in mice. In this model, micelle accumulation to tumors was significantly greater for anisotropic micelle-treated mice compared to spherical micelle-treated mice at both $8 \mathrm{hrs}(\sim 1.8$-fold greater, $\mathrm{p} \leq 0.001)$ and 24 hrs $(\sim 2.1$-fold greater, $\mathrm{p} \leq 0.0001)$.

Conclusion: Overall, this work highlights the promise of a biodegradable anisotropic micelle system to overcome multiple drug delivery challenges and enhance efficacy and safety for the treatment of brain cancer.

Keywords: GBM, verteporfin, micelle, anisotropic, poly(ethylene glycol), PEG, poly(betaamino ester), PBAE

\section{Introduction}

Glioblastoma (GBM), a grade IV astrocytoma, is one of the most elusive cancers to current treatment options of radiation and chemotherapy. ${ }^{1,2}$ The administration of the commonly used chemotherapeutic drug, Temozolomide (TMZ), in combination with radiation, post resection, has only extended the median lifespan of GBM patients to 15 months with a 5 -year survival rate of less than $5 \%$ following diagnosis. ${ }^{3}$ A major 
reason for the high GBM mortality rate is the fast (median 6.9 months) and frequent ( $90 \%$ at original site) recurrence of the tumor. $^{4,5}$

It is understood that GBM is highly regulated by the different cell types surrounding the tumor. ${ }^{6}$ Mechanical and chemical signaling promotes recurrence of the tumor and it is difficult to overcome the elaborate pathways and signals involved to attenuate further invasive growth of the tumor. $^{7-12}$ After resection, it has been suggested that the tumor cells undergo a shift to a more drug-resistant state, preventing commonly used chemotherapeutic drugs such as temozolomide (TMZ) from having a significant therapeutic effect. $^{13,14}$ Therefore, new therapeutics as well as new technologies able to deliver high drug doses to brain tumor cells are needed to provide long-term protection of the microenvironment and prevent tumor recurrence.

Nanotechnology has offered a promising ability to maintain small molecules in blood circulation, reduce clearance through the kidney, and improve biodistribution to a target organ or tissue of interest. ${ }^{15}$ Nanoparticles composed of biodegradable and biocompatible materials can be used to formulate hydrophobic molecules for minimally invasive administration through a single intravenous injection, rather than a prolonged infusion. ${ }^{16}$ Nanoparticles are particularly advantageous for use as medicines because many of the drugs used for treatment of debilitating diseases such as cancer have very low solubility in aqueous solutions, thus requiring a vehicle for efficient delivery and localization to a particular location in the body. ${ }^{17}$ Also, non-spherical nanoparticles with larger aspect ratios, which can be fabricated via either a bottom-up or top-down approach, have been demonstrated to more effectively avoid macrophage uptake and clearance, and have enhanced uptake into cancer cells compared to analogous spherical nanoparticles. ${ }^{18,19}$ In addition, the controlled biodegradability of nanoparticles can provide long-term, sustained release of small molecule drugs to tumors to maximize efficacy and decrease required dosing frequency. ${ }^{20}$

A hydrophobic small molecule verteporfin (VP) has recently been shown to attenuate GBM growth and proliferation. ${ }^{21} \mathrm{VP}$ is a benzoporphyrin derivative commonly used as a photosensitizer in photodynamic therapy for the treatment of wet-age-related macular degeneration. ${ }^{22}$ Free radicals generated from the treatment are able to suppress blood vessel formation. ${ }^{23}$ Recent studies indicate that VP is also a potent inhibitor of Yes-associated protein (YAP), a key transcriptional coactivator of the Hippo pathway and has been shown to operate as an oncoprotein in cancers. ${ }^{24}$ With
YAP being overactive in cancerous tissues, we postulated that VP could show cytotoxic effects to a greater degree on GBM cells in comparison to healthy brain stromal cells, ${ }^{7,10,12,25-27}$ as was previously shown for multiple cancers, including pancreatic, small cell lung cancer, triplenegative breast cancer, and brain cancer. ${ }^{21,28-31}$

In this study, we encapsulated VP in a micelle vehicle composed of poly(ethylene glycol)-poly( $\beta$-amino ester)poly(ethylene glycol) (PEG-PBAE-PEG) triblock copolymer. PEG was used to form the corona of the micelle to provide stealth and avoid non-specific binding to proteins in serum. PBAE is a well-studied cationic, biodegradable polymer with tertiary amines in the backbone that provide excellent buffering capacity for enhancing endosomal escape in the cytosol. ${ }^{32-34}$ It was recently shown that PBAE-based micelles can be synthesized into different aspect ratio shapes by altering the PBAE backbone hydrophobicity and PEG molecular weight. ${ }^{30}$ After following a similar protocol and confirming the synthesis of the VP-loaded micelles of two different morphologies, we investigated the effect of VP-encapsulated micelles on two patient-derived GBM cell lines and normal human astrocytes (NHA), representing the non-transformed brain parenchyma. Furthermore, we investigated the effect of micelle morphology on the pharmacokinetics and biodistribution of VP in an ectopic mouse xenograft model.

\section{Materials and Methods Materials}

1,4-Butanediol diacrylate (B4), 1,6-hexanediol diacrylate (B6), 1-(3-aminopropyl)-4-methylpiperazine (E7) (Alfa Aesar), octylamine (S8m), decylamine (S10m), acetone, dimethyl sulfoxide (DMSO), dimethylformamide (DMF), tetrahydrofuran (THF), hexane, citric acid monohydrate, disodium phosphate (Sigma-Aldrich, St. Louis, MO, USA), methoxy poly(ethylene glycol) thiol (2 $\mathrm{kDa}$ and $800 \mathrm{Da})$ (Laysan Bio, Inc.), and Verteporfin (VP (US Pharmacopeial Convention, Inc.) were purchased and used as received.

\section{Cell Culture}

All experiments were performed following the relevant guidelines and regulations from the Johns Hopkins University, Mayo Clinic, and the National Institutes of Health. Animal protocols were approved by the Mayo Clinic Animal Care Institutional and Use Committee. GBM patient-derived tumor-initiating cell line, GBM1A, was originally derived and characterized 
by Vescovi et al. ${ }^{35}$ GBM patient-derived tumor-initiating cell line, JHGBM612, was established from a patient with a butterfly GBM exhibiting pronounced invasive spread, and was characterized by our group previously. ${ }^{36}$ Normal human astrocytes (NHA) were purchased from Lonza (Walkersville, MD, USA). GBM1A and JHGBM612 were cultured as neurospheres in serum-free medium containing DMEM/F-12 (Invitrogen, Carlsbad, CA, USA) and 1\% antibiotic/antimycotic, supplemented with B27, $20 \mathrm{ng} / \mathrm{mL}$ epidermal growth factor (EGF) and $20 \mathrm{ng} / \mathrm{mL}$ basic fibroblast growth factor (bFGF) (Sigma-Aldrich). NHA were cultured in ABM Basal Medium supplemented with AGM SingleQuots Supplements necessary for the growth of astrocytes (Lonza). All cells were grown in an incubator at $37^{\circ} \mathrm{C}$ and $5 \% \mathrm{CO}_{2}$.

\section{Polymer Synthesis}

Two amphiphilic triblock copolymers were synthesized via a two-step Michael Addition reaction. 1,4 Butanediol diacrylate (B4) was reacted with octylamine ( $\mathrm{S} 8 \mathrm{~m}$ ) by Michael Addition reaction at a molar ratio of $1.15: 1$ at $90^{\circ} \mathrm{C}$ for 72 hrs to yield acrylate-terminated hydrophobic (B4S8m) PBAE base polymer. In another reaction, 1,6 hexanediol diacrylate (B6) was reacted with decylamine (S10m) by Michael Addition reaction at a molar ratio of $1.15: 1$ at $90^{\circ} \mathrm{C}$ for 24 hrs to yield another acrylate-terminated hydrophobic PBAE base polymer (B6S10m). Both base polymers were precipitated twice in hexane and then dried under vacuum with desiccant overnight. The structure and molecular weight of the base polymers were confirmed using Bruker Avance III $500 \mathrm{MHz}^{1} \mathrm{H}$ NMR spectrometer in $\mathrm{CDCl}_{3}$. Following a protocol described by $\mathrm{Kim}$ et al, the $\mathrm{B} 4 \mathrm{~S} 8 \mathrm{~m}$ was then endcapped by thiol-ene Michael Addition with 2 kDa mPEGthiol in DMSO, using 1-(3-aminopropyl)-4-methyl-piperazine (E7) $(1: 2.5: 0.25 \mathrm{w} / \mathrm{w} / \mathrm{w})$ as a primary amine-containing catalyst. ${ }^{34}$ The endcapping reaction was performed for 24 hrs at $50^{\circ} \mathrm{C}$ while stirring. A rotary evaporator was used to remove DMSO from the product, referred to as PP1. Afterwards, the resulting product was purified through precipitation in hexane, and this was repeated thrice. For B6S10m endcapping, a similar protocol was followed; however, $800 \mathrm{Da}$ mPEG-thiol was used. The structures of PP1 and PP2 were confirmed using ${ }^{1} \mathrm{H} \mathrm{NMR}$ in $\mathrm{CDCl}_{3}$.

\section{Micelle Synthesis}

Spherical VP-loaded micelles (sVPM) and filamentous VP-loaded micelles (fVPM) were synthesized using the following nanoprecipitation protocol. For sVPM synthesis, PP1 was dissolved in DMF at $20 \mathrm{mg} / \mathrm{mL}$ and then mixed with an equivalent volume of $1 \mathrm{mg} / \mathrm{mL}$ VP solution in DMSO (5 wt $\%$ feed ratio). Five hundred microliters of the resulting solution was added slowly dropwise to $1.5 \mathrm{~mL}$ of stirring deionized (DI) water at $500 \mathrm{rpm}$ in a scintillation vial. The samples were then immediately sonicated in a water bath sonicator for $1 \mathrm{~min}$ before returning to the stir plate for 4 hrs. fVPM were synthesized very similarly; however, PP2 was dissolved in acetone. Unloaded micelles were also prepared by replacing the VP solution in DMSO with pure DMSO. After $4 \mathrm{hrs}$ of spinning, the solution was filtered through a $10-\mathrm{kDa}$ MWCO filter. The filtrate was collected and added to a Sephadex column with Sephadex S-500 High Resolution. The tubes were spun at $800 \mathrm{~g}$ for 3 mins. The filtrate was collected and then filtered with a $0.22-\mu \mathrm{m}$ PTFE syringe filter. Then, the resulting solution was aliquoted into several pre-weighed tubes and lyophilized. A $10 \%$ sucrose solution was included with the sVPM as a cryoprotectant.

\section{Micelle Characterization}

Lyophilized sVPM and fVPM were resuspended at $1 \mathrm{mg}$ / $\mathrm{mL}$ in DI water and then sized using dynamic light scattering (DLS) with Malvern Zetasizer Nano ZS (Malvern Instruments, Malvern, U.K.). In addition, Zetasizer was used to measure the zeta potential of the micelles in $10 \mathrm{mM} \mathrm{NaCl}$ at $1 \mathrm{mg} / \mathrm{mL}$. Moreover, transmission electron microscopy (TEM) was used to confirm size and examine the morphology of the micelles. Micelles were resuspended in DI water at $1 \mathrm{mg} / \mathrm{mL}$ and then pipetted gently onto a carbon grid $(10 \mu \mathrm{L})$. The grid was left until the solution fully evaporated and then was submerged for in $0.5 \%$ uranyl acetate for $30 \mathrm{sec}$, then in DI water, and left to fully dry. The grids were then imaged using a Philips/FEI BioTwin CM120 TEM.

\section{VPM Loading Capacity}

VP was released from micelle core by dissolving lyophilized micelles in DMSO at $1 \mathrm{mg} / \mathrm{mL}$. The resulting solution was then added to a dark 96-well plate, and several serial half dilutions were made. The fluorescence signals of the wells were measured with a Synergy 2 plate reader (BioTek) at an excitation wavelength of $420 \mathrm{~nm}$ and an emission wavelength of $680 \mathrm{~nm}(\mathrm{n}=3)$. VP concentration was then determined using a standard curve to interpret the fluorescence intensity values. The VP loading capacity (LC) and loading efficiency (LE) were then calculated according to the following formulas: 


$$
\begin{aligned}
& \mathrm{LC}(\%)=\frac{\text { mass of VP }}{\text { mass of polymer }} \times 100 \\
& \mathrm{LE}(\%)=\frac{\text { yielded VP mass }}{\text { fed VP mass }} \times 100
\end{aligned}
$$

\section{Evaluation of Solubility}

To measure VP solubility in both the unencapsulated and micelle-encapsulated forms, samples were mixed with $1 \times$ PBS at an equivalent concentration of $2 \mathrm{mg} / \mathrm{mL}$ VP. Equivalent volumes $(50 \mu \mathrm{L})$ were added into a 96-well plate, and turbidity (absorbance) was measured with a plate reader at $550 \mathrm{~nm}(\mathrm{n}=3)$.

\section{VP Release Kinetics}

Micelles were resuspended at $1 \mathrm{mg} / \mathrm{mL}$ inside citratephosphate buffers maintaining $\mathrm{pH}$ at $5,6.5$, and 7.4 to simulate the local environments of endosomes, extracellular tumor tissue, and normal blood vessels, respectively. Buffers were produced by mixing $0.1 \mathrm{M}$ citric acid monohydrate and $0.2 \mathrm{M}$ disodium phosphate at different $\mathrm{v} / \mathrm{v}$ ratios to produce the desired $\mathrm{pHs}$. One milliliter of resuspended micelles was kept at $37^{\circ} \mathrm{C}$ in between timepoints $(\mathrm{n}=3)$. At 1, 3, 5, and $10 \mathrm{hrs}$ timepoints, micelle solutions were centrifuged at $200,000 \mathrm{rpm}$ for $20 \mathrm{mins}$ at $4^{\circ} \mathrm{C}$. Eight hundred microliters of the supernatant was removed and replaced with a fresh buffer of the same $\mathrm{pH}$. The micelle pellet was resuspended and returned to $37^{\circ} \mathrm{C}$ until future timepoints. The collected supernatants were frozen, lyophilized and then resuspended with DMSO to solubilize the VP in the release samples. The samples were centrifuged at 15,000 rpm to pellet the buffer salts, but leave the solubilized VP in the supernatant. After centrifuging, the supernatant of each sample was added to a dark, flatbottom 96-well plate and then fluorescence intensity was measured with a plate reader $(420 \mathrm{~nm}$ excitation, $680 \mathrm{~nm}$ emission wavelengths). The concentration of VP in each tube was determined using a $\mathrm{pH}$-specific standard curve previously developed.

\section{Cellular Uptake}

GBM1A, JHGBM612, and NHA cells were seeded at 15,000 cells per well in 96-well plates in $100 \mu \mathrm{L}$ of media, and incubated in an atmosphere of $5 \% \mathrm{CO}_{2}$ at $37^{\circ} \mathrm{C}$ for $24 \mathrm{hrs}$. Equivalent final VP concentrations of free VP, fVPM, and sVPM ranging from 7.8125 to 125.0 $\mathrm{nM}$ were incubated with the cells for $1.5 \mathrm{hrs}(\mathrm{n}=4)$. After incubation, cells were then washed three times with heparin in $1 \times$ PBS $(50 \mu \mathrm{g} / \mathrm{mL})$ to remove VP possibly bound electrostatically to the cell membranes, trypsinized, neutralized with FACS buffer ( $2 \%$ FBS in $1 \times$ PBS), transferred to a round-bottom 96-well plate, centrifuged, resuspended with FACS buffer, and then analyzed by flow cytometry (BD Accuri C6 with HyperCyt adaptor). The results were then analyzed by FlowJo 7.6.5 software using FSC-H vs SSC-H gating for singlet cells and FL3 vs FSC$\mathrm{H}$ gating for VP-positive cells. All wells included in data analysis had at least 500 singlet events per well.

\section{Cell Viability}

GBM1A, JHGBM612, and NHA cells were seeded at 15,000 cells per well in 96 well plates in $100 \mu \mathrm{L}$ of media, and incubated in an atmosphere of $5 \% \mathrm{CO}_{2}$ at $37^{\circ} \mathrm{C}$ for $24 \mathrm{hrs}$. Equivalent final VP concentrations of free VP, fVPM, and SVPM ranging from 3.90625 to $500.0 \mathrm{nM}$ were incubated with the cells for $2 \mathrm{hrs}(\mathrm{n}=4)$. Following treatment, cells were washed 3 times with $1 \times$ PBS, and incubated for $24 \mathrm{hrs}$ in $100 \mu \mathrm{L}$ of fresh media. Viability was then determined by incubating the cells with $100 \mu \mathrm{L}$ of CellTiter 96AqueousOne MTS assay solution in complete media $(1: 5 \mathrm{v} / \mathrm{v})$ in an atmosphere of $5 \% \mathrm{CO}_{2}$ at $37^{\circ} \mathrm{C}$ for $2 \mathrm{hrs}$. The resulting absorbance of the wells was measured using a plate reader at $490 \mathrm{~nm}$. Brightfield images of each condition were taken right before incubation with MTS assay solution.

\section{VPM Pharmacokinetics and Biodistribution}

All animal protocols were approved by the Mayo Clinic Animal Care Institutional and Use Committee. Athymic nude mice 5-7 weeks of age were inoculated with $2 \times 10^{6}$ human glioblastoma (GBM1A) cells in matrigel solution in the flank. Once tumors reached $150 \mathrm{~mm}^{3}$, they were randomized into four different groups ( $\mathrm{n}=4$ each) for blood half-life and tissue distribution studies. For each study, one group was injected in tail-vein with spherical micelles while the other group was injected with filamentous micelles. These micelles were formulated following the protocol above with near-infrared (NIR)-dye (Lumiprobe) encapsulated in place of VP for fluorescence imaging, lyophilized, and reconstituted to $1.75 \mathrm{mg} / \mathrm{mL}$ of NIR-dye prior to injection. To study pharmacokinetics, blood was collected from the saphenous vein at 5, 10, 30 mins, 1, 2, 4 , and $8 \mathrm{hrs}$ timepoints post-injection into heparinized capillary tubes. Fluorescence in capillary tubes was 
imaged using IVIS. To study biodistribution, the whole animal live image was acquired using IVIS at $0,0.5,1,2$, 4,8 , and 24 hrs post-injection. Then, animals were sacrificed at $24 \mathrm{hrs}$ and organs (liver, spleen, kidneys, bladder, lungs, and heart) were harvested for imaging individually with IVIS. An ROI was drawn around each organ and fluorescence intensity was quantified with Living Image 3.2 software. To calculate percent distribution, each fluorescence intensity value was normalized to the sum of fluorescence intensity values from all measured organs.

\section{Statistics}

GraphPad Prism 6 software package was used to perform statistical analysis. One-way ANOVA with Bonferroni post hoc test was used to compare all pairs, or Student's $t$-test was used to compare two conditions. Two-way ANOVA with Tukey post hoc test was used for multiple comparisons $(* \mathrm{p} \leq$ $0.05, * * \mathrm{p} \leq 0.01, * * * \mathrm{p} \leq 0.001, * * * * \mathrm{p} \leq 0.0001)$. $\mathrm{p}$-values less than 0.05 were considered statistically significant.

\section{Results and Discussion}

\section{Synthesis and Characterization of PBAE Base Polymer and Triblock PEG-PBAE- PEG Copolymer}

PBAE base polymers were synthesized via Michael Addition (1.15:1 ratio of diacrylate to alkylamine monomer). Resulting molecular weights for B4S8m and B6S10m were 5274 Da and $6471 \mathrm{Da}$, respectively. As reported in related studies of particle thermodynamics and assembly, the greater hydrophobicity of B6S10m compared to B4S8m increases the critical packing parameter $\left(v / \alpha_{0} l_{\mathrm{c}}\right.$, where $v$ is the volume of the hydrocarbon core, $\alpha_{0}$ is the effective head group area, and $l_{\mathrm{c}}$ is the hydrocarbon chain length), producing more wormlike micelles. ${ }^{37}$ B4S8m and B6S10m were end-capped with 2000 and 800 Da mPEG-thiol via Michael Addition to synthesize PEGylated polymers, PP1 and PP2, respectively. By endcapping B6S10m with a lower molecular weight PEG compared to B4S8m, this decreased the critical packing parameter variable, $\alpha_{0}$, to increase the overall critical packing parameter and generate a more filamentous shape. The reactions were confirmed through 1H NMR spectrum in Figures S1A and $\underline{B}$. The PP1 and PP2 spectrum show reduced area for peaks a-c, which correspond to hydrogens of the base polymer diacrylates. The reaction efficiencies were $77 \%$ and $67 \%$ for PP1 and PP2, respectively.

\section{Micelle Characterization}

Micelles were synthesized via nanoprecipitation and subsequently characterized in terms of size, shape and surface charge. TEM images in Figure 1A show that sVPM were spherical, while fVPM had a filamentous, wormlike shape. These morphologies and aspect ratios were highly reproducible and did not exhibit batch-to-batch variability. As shown in Figure 1B, DLS determined that the sphere-equivalent hydrodynamic diameters for sVPM and fVPM were $156 \pm 2 \mathrm{~nm}$ and $350 \pm 20 \mathrm{~nm}$, respectively. Given that these are intensityweighted hydrodynamic diameters, TEM exhibited particles of a smaller size, particularly for sVPM. In addition, the PDI values were $0.30 \pm 0.02$ and $0.46 \pm 0.03$, respectively. The larger aspect ratio for fVPM can explain the larger size and PDI compared to sVPM, given that DLS calculates size assuming spherical particles in the Stokes-Einstein equation. The zeta potentials (Figure 1C) for sVPM and $\mathrm{FVPM}$ in $10 \mathrm{mM} \mathrm{NaCl}$ were $2 \pm 6 \mathrm{mV}$ and $-3 \pm 4 \mathrm{mV}$, corroborating that PEG is on the surface of both micelles due to the neutral charge measured. The LC was determined to be $5.62 \%$ and $6.82 \%$, for sVPM and fVPM, respectively. The LC differed less than $1 \%$ between repeated batches of both formulations. Although the initial feed ratio of VP to polymer was $5 \mathrm{wt} \%$, a $>5 \%$ LC most likely occurs due to a loss of polymer in the post-synthesis centrifuging and filtering steps. The LE was determined to be $33.7 \%$ and $14.6 \%$, for sVPM and fVPM, respectively. The lower polymer yield for fVPM ( 10\%) compared to sVPM ( 25\%) can explain the greater LC, but lower LE. It is possible that the longer PBAE backbone for fVPM may prevent some hydrophobic chains from organizing in the core of the micelle, leading to more unstable self-assemblies.

\section{Solubility Enhancement}

To overcome a very poor water solubility, hydrophobic VP was encapsulated in micelles with a hydrophobic interior and hydrophilic PEG exterior. Solubility enhancement was determined by analyzing the turbidity of PBS solutions with free VP or an equivalent mass of VP encapsulated inside micelles. Absorbance/turbidity was measured at a peak wavelength of VP absorption/turbidity (550 nm). Figure 1D shows lower absorbance for encapsulated VP compared to free VP. The very low solubility of free VP in PBS results in high turbidity which decreases light penetration, increasing the measurement value for absorbance. The greater solubility of micelles in PBS creates a clearer, more homogeneous solution, allowing more light to penetrate through the sample, decreasing the level of 
A

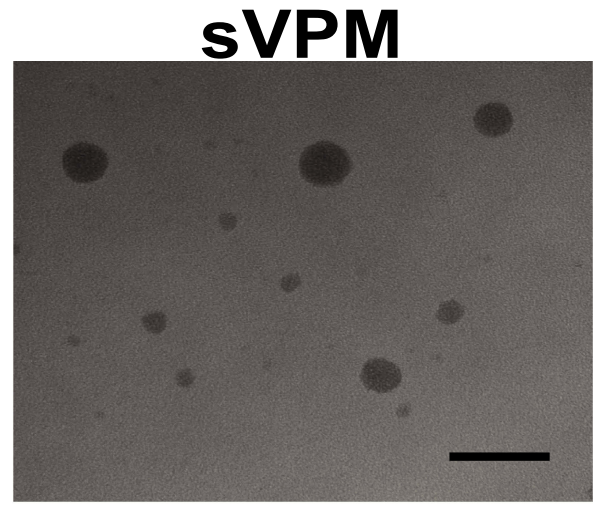

fVPM

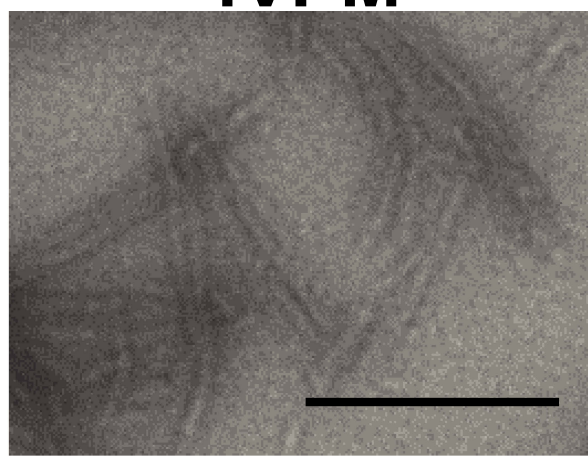

B

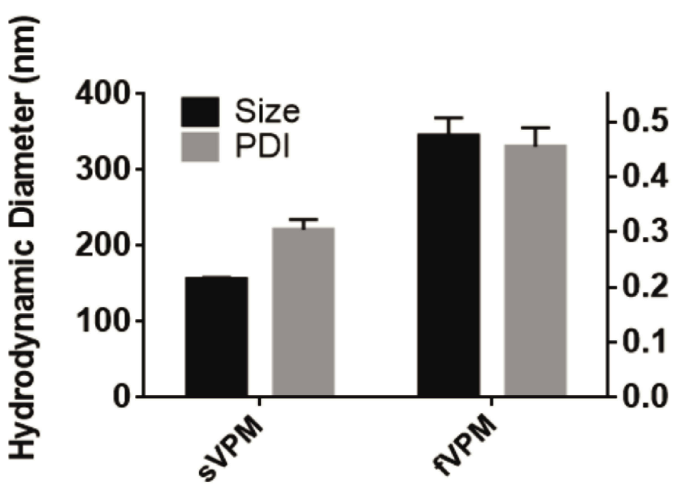

D

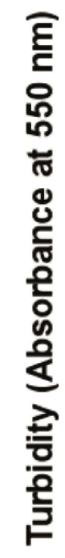

C

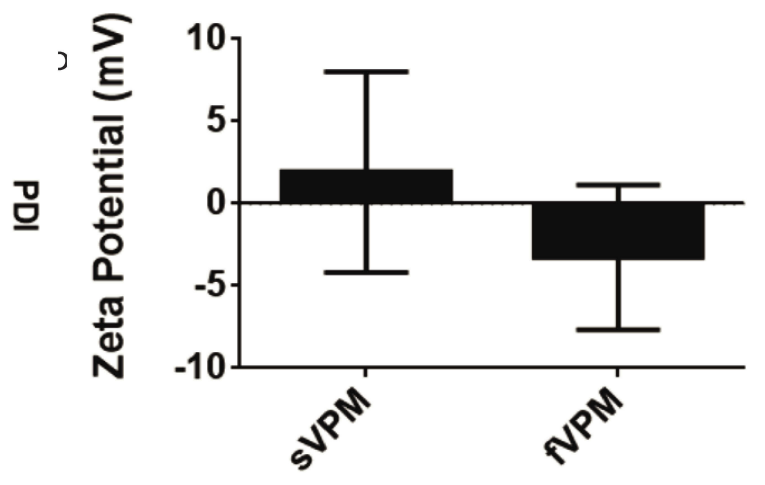

E

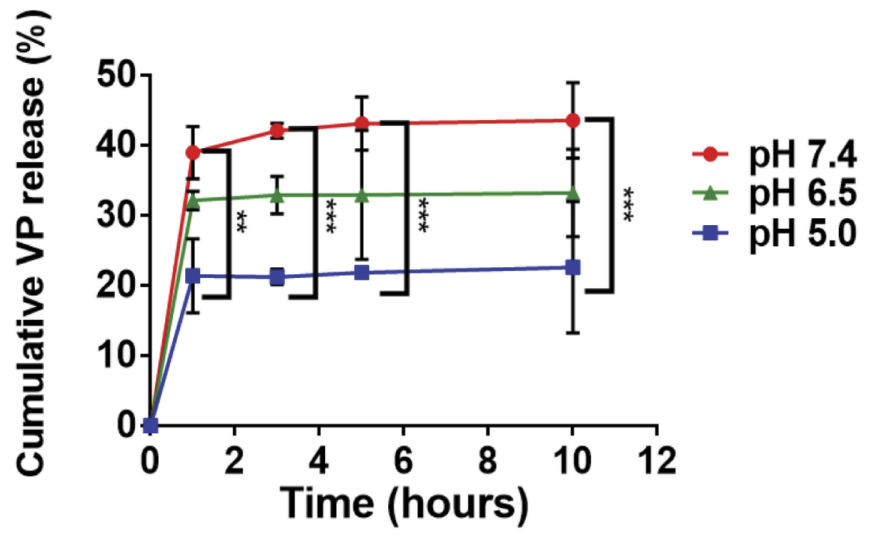

Figure I Triblock copolymer micelles loaded with VP exhibit tunable morphology, pH-sensitivity, and aqueous solubility. (A) Representative TEM images of both sVPM (left, scale bar $=100 \mathrm{~nm}$ ) and fVPM (right, scale bar $=500 \mathrm{~nm}$ ), (B) size and polydispersity index (PDI) of micelles $(n=3$, mean \pm SD), (C) zeta potential of sVPM and fVPM in I0 mM $\mathrm{NaCl},(D)$ turbidity measured with both free and encapsulated VP in $\mathrm{FPM}$ at $2 \mathrm{mg} / \mathrm{mL} \mathrm{VP}$ in $\mathrm{I} \times \mathrm{PBS}(\mathrm{n}=3$, mean \pm SD), (E) VP release from fVPM at $0,1,3,5$, and $10 \mathrm{hrs}$ timepoints in buffers prepared at $\mathrm{pH} 5.0,6.5$, and $7.4(\mathrm{n}=3$, mean $\pm \mathrm{SD}$, one-way ANOVA with Bonferroni's multiple comparisons test $(* * \mathrm{p} \leq 0.0 \mathrm{I}$, ***p $\leq 0.00 \mathrm{I})$ ).

absorbance/turbidity measurement. This confirms that VPencapsulation inside micelles that display hydrophilic PEG chains on the corona enhances the solubility of VP, and provides a more usable and practical formulation for an in vivo environment.

\section{$\mathrm{PH}$-Sensitive Release of VP from $\mathrm{fVPM}$}

PBAE polymers have tertiary amines in their backbones which provide excellent buffering capacity in an acidic environment, leading to efficient endosomal escape inside cells. pH-sensitive release was evaluated by resuspending 
fVPM at $1 \mathrm{mg} / \mathrm{mL}$ inside citrate-phosphate buffers at $\mathrm{pH}$ $5,6.5$, and 7.4 in order to simulate the local environments of endosomes, extracellular tumor microenvironment, and blood vessels, respectively. Figure 1E shows the release plots at all three $\mathrm{pH}$ values over $10 \mathrm{hrs}$. All three plots show similar kinetic trends, but differing percentages of total VP mass released with $\mathrm{pH} 7.4$ showing the greatest mass of VP release, $\mathrm{pH} 6.5$ showing an intermediate VP mass release, and $\mathrm{pH} 5.0$ showing the lowest percentage of VP released. This trend is comparable with that observed by Tzeng and Green, in which PBAE polyplexes were used. $^{38}$ Table 1 summarizes the key chemical and physical characteristics of sVPM and IVPM.

\section{VP Internalization in Patient-Derived Glioma and Astrocyte Cells}

To evaluate the level of VP-loaded micelle and free VP uptake in GBM1A, JHGBM612, and NHA, flow cytometry was performed given the fluorescence property of VP. Cells were incubated with VP at equivalent concentrations ranging from 7.81 to $125 \mathrm{nM}$ for $1.5 \mathrm{hrs}$. Uptake efficiency was first measured to determine the number of cells out of the whole population that showed positive fluorescence in the PE channel. We did not observe cell death due to careful preparation of the samples. In addition, no cytotoxicity was expected from the VP treatment given the very short incubation time. As shown in Figure S2A and C, nearly $100 \%$ of cells had successful uptake for all formulations, sVPM, fVPM, and free VP, at every concentration in GBM1A and JHGBM612. In Figure S2E, NHA exhibits a dose-dependent uptake efficiency, with sVPM showing the highest uptake efficiency, followed by FVPM and then free VP. Cellular uptake saturation was observed for all treatments at approximately 62.5 $\mathrm{nM}$. Geometric mean of fluorescence intensity was also

Table I Summarized Chemical and Physical Characteristics of sVPM and FPM

\begin{tabular}{|l|l|l|}
\hline $\begin{array}{l}\text { Chemical/Physical } \\
\text { Characteristics }\end{array}$ & sVPM & fVPM \\
\hline PBAE base polymer/MW (Da) & B4S8m/5274 & B6SI Om/647I \\
PEG-SH MW (Da) & 2000 & 800 \\
Morphology & Spherical & Filamentous \\
Hydrodynamic diameter (nm) & $156 \pm 2$ & $350 \pm 20$ \\
PDI & $0.30 \pm 0.02$ & $0.46 \pm 0.03$ \\
Zeta potential (mV) & $2 \pm 6$ & $-3 \pm 4$ \\
Loading capacity (\%) & 5.62 & 6.82 \\
Loading efficiency (\%) & 33.7 & 14.6 \\
\hline
\end{tabular}

evaluated to measure the relative amounts of VP entering each cell. The intensity was analyzed only from the VP+ cells in order to eliminate bias from uptake efficiency. The results shown in Figure S2B, D and F demonstrate that VP per cell increased in a dose-dependent manner for all cell types and for all treatments. Figure $\mathrm{S} 2 \mathrm{G}$ and $\underline{\mathrm{H}}$ highlight the statistically significant differences in the averaged geometric mean uptake for all three formulations between different cell types for 62.5 and $125 \mathrm{nM}$ treatments, respectively. Figure 2A demonstrates significantly lower uptake efficiencies in NHA compared to GBM1A and JHGBM612 for all formulations treated from 7.81 to $31.3 \mathrm{nM}$, except sVPM at $31.3 \mathrm{nM}$. Figure $2 \mathrm{~B}$ and $\mathrm{C}$ show that the normalized uptake values for NHA are very low compared to GBM1A and JHGBM612. For example, statistical analysis of fVPM uptake at $62.5 \mathrm{nM}$ VP showed that the differences between GBM1A and NHA ( $\mathrm{p} \leq 0.05$ ) and JHGBM612 and NHA ( $\leq \leq 0.0001)$ were significant. At $125 \mathrm{nM}$, fVPM uptake was significantly higher only in JHGBM612 in comparison to NHA ( $\mathrm{p} \leq$ $0.001)$. For all cell types and the majority of tested concentrations, sVPM showed the greatest geometric mean, suggesting a larger VP dosage entering the cells compared to fVPM or free VP. It has been demonstrated that cancer cell uptake of spherical-shaped nanoparticles happens more readily than larger aspect ratio nanoparticles. ${ }^{18,39-41}$ It is postulated that rod-shaped nanoparticles internalize slower into cells because their contact angle in relation to the cell membrane can vary, whereas spherical particles, which are symmetrical, have a constant contact angle to the cell membrane. For example, if a rod-shaped particle approaches a cell with its long axis parallel to the cell membrane, it is more difficult for the cell to "wrap" around the particle. ${ }^{42}$ Moreover, the high uptake efficiencies suggest that the PEG corona on these micelles may still permit some level of protein adsorption onto the micelle surface. This can enhance electrostatic interaction between the micelles and cell membranes, increasing endocytosis of the micelles. It has been reported previously that grafting 3.4-kDa PEG chains onto polystyrene nanoparticles demonstrated $90 \%$ reduction of protein adsorption compared to uncoated nanoparticles. ${ }^{43}$ Thus, the lower molecular weight PEG used in these studies would most likely permit a greater level of protein adsorption. In addition, macropinocytosis may play a role in this uptake.

\section{VP-Induced Cell Death in Patient-Derived Glioma and Astrocyte Cells}

In order to evaluate the potency of VP as a chemotherapeutic for patient-derived GBM cell lines and its effect on NHA, 

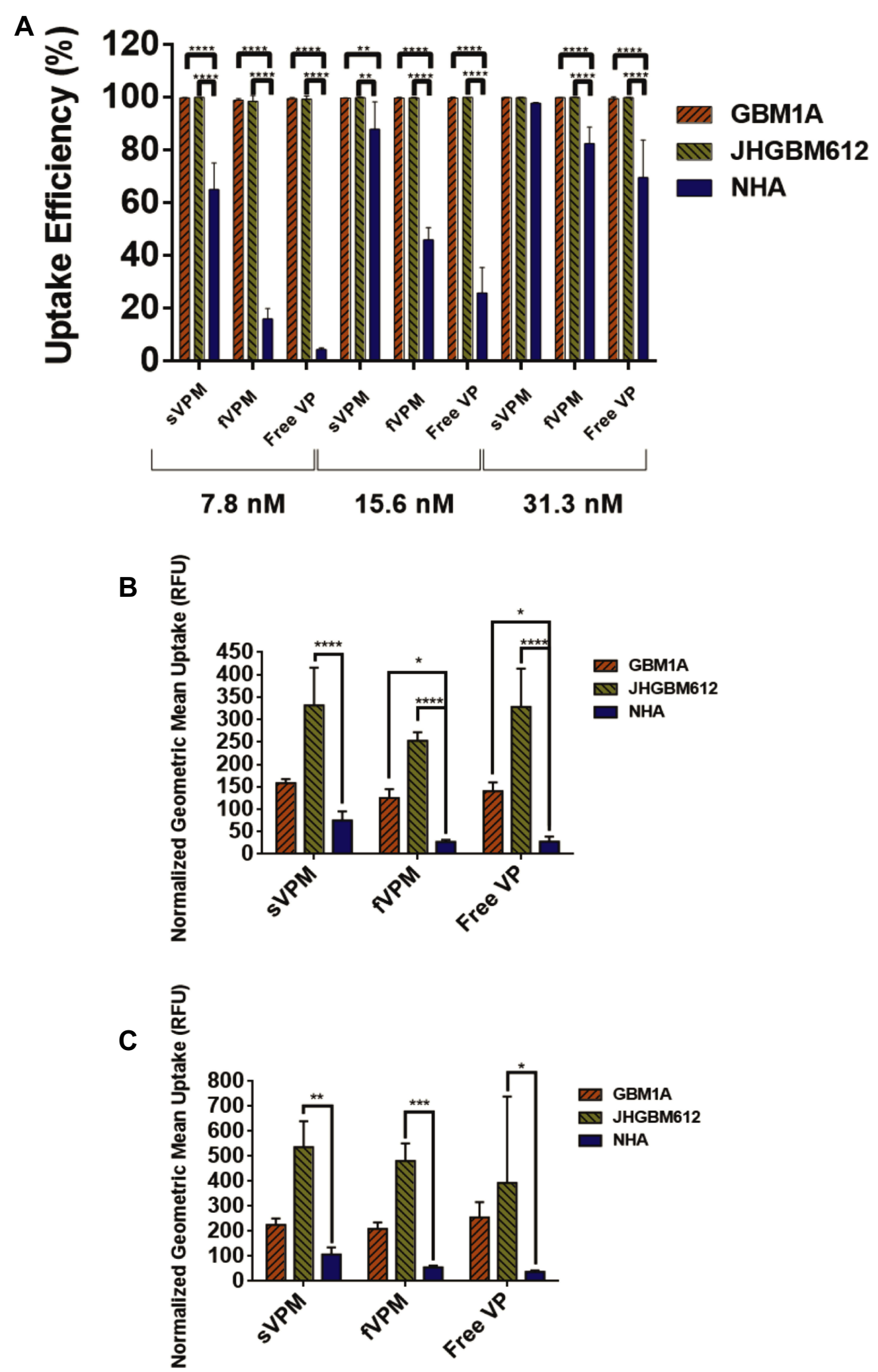

Figure 2 NHA demonstrate significantly lower uptake efficiency and normalized geometric mean uptake of free VP, sVPM, and fVPM compared to patient-derived GBMs. (A) Consolidated uptake efficiency data from all three cell types and treatments at 7.8, I5.6, and 3I.3 nM ( $\mathrm{n}=4$, mean \pm SD, one-way ANOVA with Bonferroni's multiple comparisons test (**p $\leq 0.01$, ****p $\leq 0.000 \mathrm{I})$ ). (B and C) Consolidated normalized geometric mean measurements at $62.5 \mathrm{nM}(\mathbf{B})$ and $125 \mathrm{nM}$ (C) VP treatment for all three tested cell types $\left(n=4\right.$, mean $\pm S D$, one-way ANOVA with Bonferroni's multiple comparisons test $\left({ }^{*} p \leq 0.05\right.$, ** $p \leq 0.0$ I, *** $p \leq 0.00$ I, ***** $\leq 0.000 \mathrm{I})$ ). Cells were normalized to untreated controls of the same cell type. 

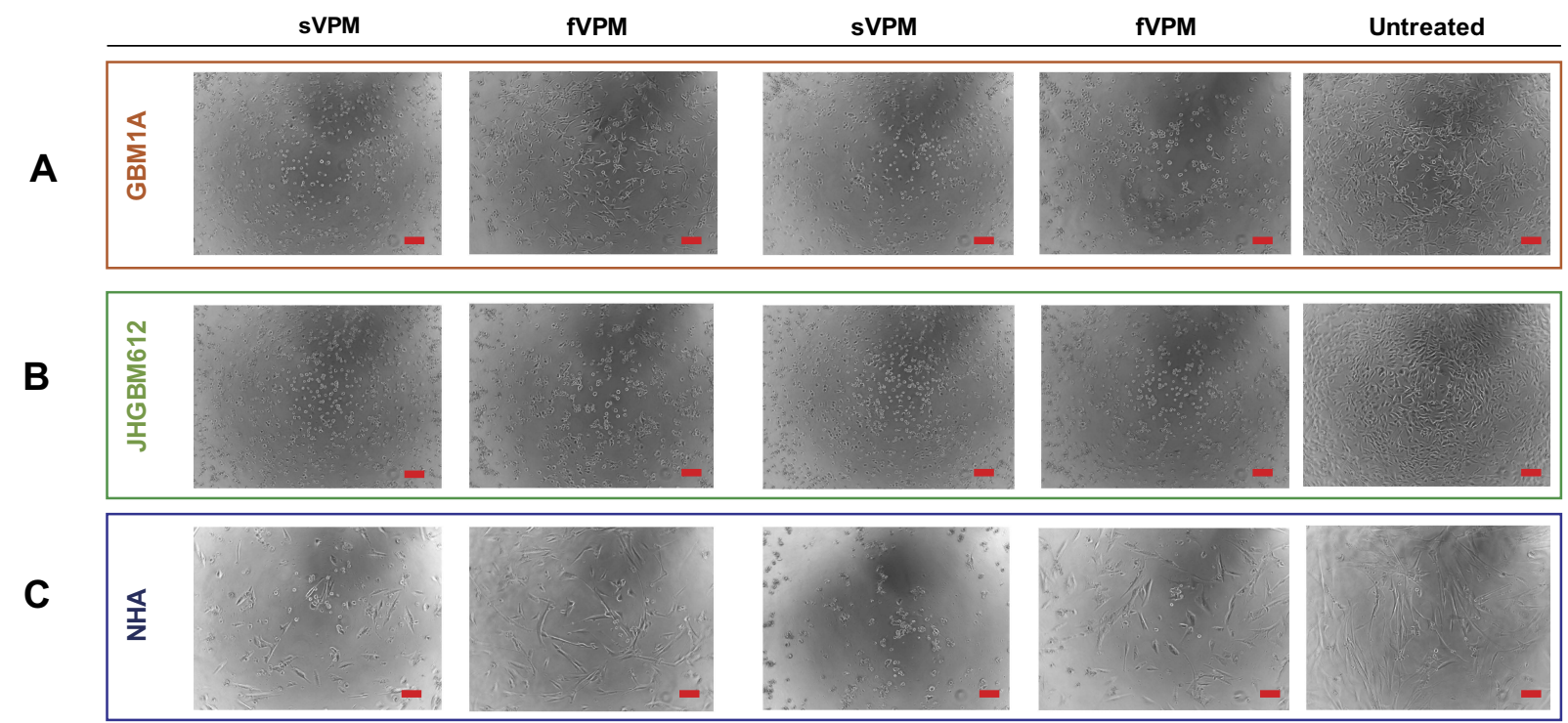

D

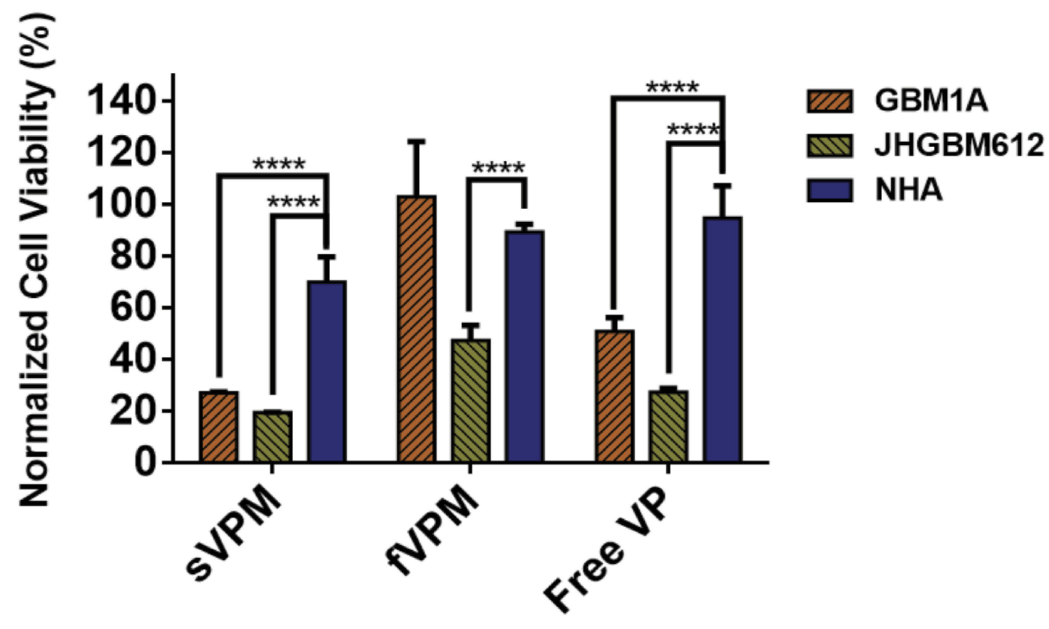

E

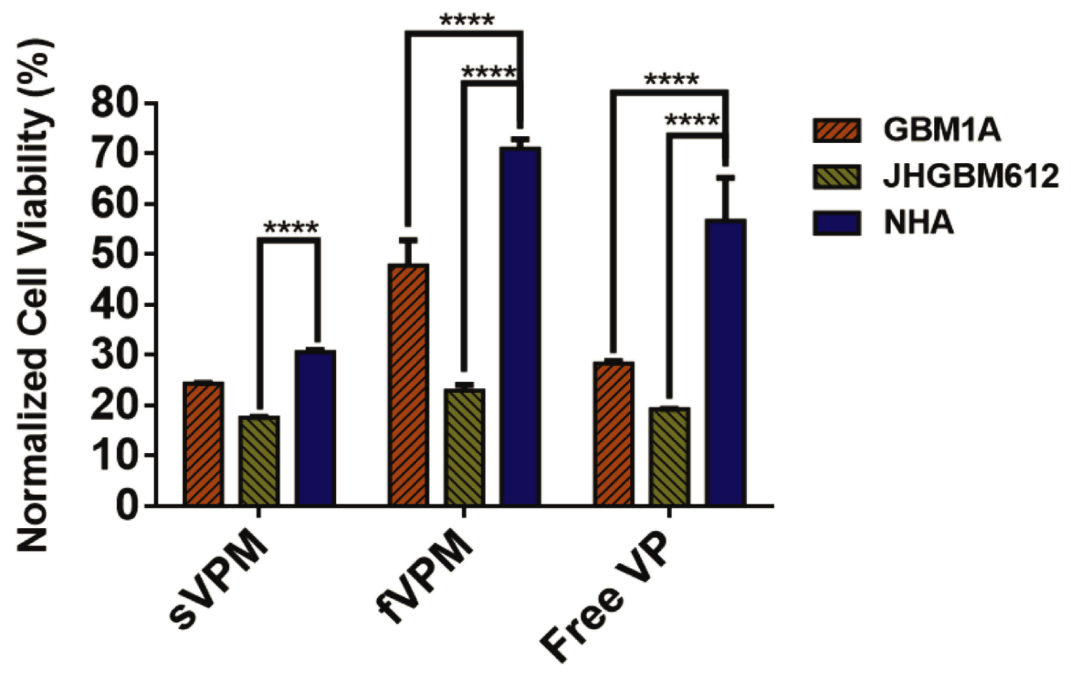

Figure 3 NHA viability is significantly greater than patient-derived GBMs after free VP, sVPM, and fVPM treatments. (A-C) Representative brightfield images for corresponding cell types after $62.5 \mathrm{nM}$ VP (left), $125 \mathrm{nM}$ VP (center) and no treatment (right) (scale bar = $100 \mu \mathrm{m}$ ). (D and E) Consolidated normalized cell viability measurements at $62.5 \mathrm{nM}(\mathrm{D})$ and $125 \mathrm{nM}$ (E) VP treatment for all three tested cell types $(\mathrm{n}=4$, mean \pm SD, one-way ANOVA with Bonferroni's multiple comparisons test $(* * * * p \leq 0.000 \mathrm{I})$ ). Cells were normalized to untreated controls of the same cell type. 
sVPM, fVPM, and free VP were added to GBM1A, JHGBM612, and NHA for a $2 \mathrm{hr}$ treatment period at final VP concentrations between 3.9 and $500 \mathrm{nM}$. And, $24 \mathrm{hrs}$ later, the cells were imaged (Figure $3 \mathrm{~A}-\mathrm{C}$ ) and their metabolic activities were measured with MTS. At $15.6 \mathrm{nM}$ and below, there was no cytotoxicity observed for any of the cell types. Interestingly, $62.5 \mathrm{nM}$ and/or $125 \mathrm{nM}$ VP treatments displayed the greatest cytotoxicity differential among the three different treatments in all three cell types. Figure 3D shows that at $62.5 \mathrm{nM}$, sVPM-treated GBM1A, JHGBM612, and NHA exhibited viabilities of $27 \%, 19 \%$, and $70 \%$, respectively. For fVPM treatment, viability was 103\%, $47 \%$, and $89 \%$, respectively. And for free VP, viability was $51 \%, 27 \%$, and $95 \%$, respectively. The difference in viability was significant between individual GBM lines and NHA $(\mathrm{p} \leq$ 0.0001), for all conditions and treatments, except fVPMtreated GBM1A cells and NHA. IVPM did not show greater cytotoxicity in any of the cell lines compared to sVPM, at both 62.5 and $125 \mathrm{nM}$. Figure $3 \mathrm{E}$ shows that at $125 \mathrm{nM}$, sVPM-treated GBM1A, JHGBM612, and NHA exhibited viability levels of $24 \%, 18 \%$, and $31 \%$, respectively. At 125 nM fVPM treatment, viability levels were 48\%, 23\%, and $71 \%$ in GBM1A, JHGBM612, and NHA, respectively. For $125 \mathrm{nM}$ free VP, similar viability values were observed for GBM1A (28\%) and JHGBM612 (19\%); however, for NHA, viability increased to $57 \%$. For $125 \mathrm{nM}$, all comparisons between GBM1A and NHA, and JHGBM612 and NHA were statistically significant $(\mathrm{p} \leq 0.0001)$ for $\mathrm{sVPM}$, fVPM, and free VP, except for sVPM between GBM1A and NHA. The shown brightfield images in Figure 3A-C align with the viability values aforementioned. Moreover, Figure S3A-C displays the comprehensive viabilities for all three cell types after sVPM, fVPM, or free VP treatments. Regarding potential clinical translation, while fVPM does not achieve as high killing of GBM cells as is observed for sVPM, the combination of diminished cytotoxicity towards NHA and the advantageous pharmacokinetic and biodistribution properties of these micelles may provide several therapeutic benefits over sVPM for future in vivo treatments.

In addition, as shown in Figure S3D and $\underline{\mathrm{E}}$, the difference in average normalized cell viability for all three treatments between the three different cell types at $62.5 \mathrm{nM}$ and $125 \mathrm{nM}$ VP is statistically significant. For $62.5 \mathrm{nM}$ VP treatment, there is an average $24 \%$ higher cell viability for NHA compared to GBM1A ( $\mathrm{p} \leq 0.0001)$, and $53 \%$ higher cell viability for NHA compared to JHGBM612 ( $\mathrm{p} \leq 0.0001)$. The differing cytotoxicity observed in the treatments between GBM cells and NHA can be rationalized by the varying levels of
VP entering each cell type. According to the normalized geometric mean fluorescence intensity for cellular uptake results in Figure S2G $(62.5 \mathrm{nM})$ and $\underline{\mathrm{H}}(125 \mathrm{nM})$, the difference among all three treatments is statistically significant when comparing both GBM1A and NHA ( $\mathrm{p} \leq 0.001,0.05)$, and JHGBM612 and NHA ( $\mathrm{p} \leq 0.0001$ for both). More specifically, GBM1A cells have roughly more than twofold greater VP uptake per cell for all formulations compared with NHA, and JHGBM612 cells have approximately sixfold greater VP uptake per cell compared to NHA.

Previous studies have demonstrated that relative amounts of nanoparticle uptake between different cell types is dependent on the cell size and shape. ${ }^{44,45}$ Astrocytes exhibit longer neurite-like projections and a more stretched appearance compared to the patient-derived GBM cell lines used in these studies. It is possible that the astrocyte neurites might sterically hinder nanoparticle uptake into the cell body and cause other differences in endocytosis. Furthermore, it is known that the highly invasive nature of GBM cells is aided by the degradation of the cancer cell extracellular matrix (ECM) via protease secretions. ${ }^{46}$ Reduced ECM surrounding GBM cells compared to astrocytes may enhance the uptake of the micelles into GBM cells. In addition to enhanced uptake into the cancer cells, the YAP-TEAD pathway, the primary target of VP, is activated more in cancer cells compared to healthy cells. This may enhance the ability for VP to elicit a heightened cytotoxic effect in GBM cells compared to NHA. It is important to note that the NHA cell line, which is established from a nonneoplastic source, may not necessarily represent similar molecular pathway activation such as YAP-TEAD4 signaling, observed in tumor-associated astrocytes. These tumorsurrounding glial cells have been shown to undergo phenotypic and genotypic alterations compared to those in a normal, healthy brain parenchyma. ${ }^{47}$ While further investigation is warranted to identify the mechanisms involved, it is important to highlight that the more cytotoxic nature of all VP treatments against GBM cells compared to astrocytes provides a critical therapeutic window to kill the cancer cells while attenuating the same damage against the healthy brain parenchyma.

\section{Pharmacokinetics and Biodistribution in Ectopic Mouse Xenograft Tumor Model}

Our group has previously demonstrated that filamentous micelles are able to avoid macrophage uptake more effectively than spherical micelles in vitro. ${ }^{30}$ To test the capability of fVPM to evade macrophages and provide prolonged systemic circulation in vivo in comparison to its spherical 


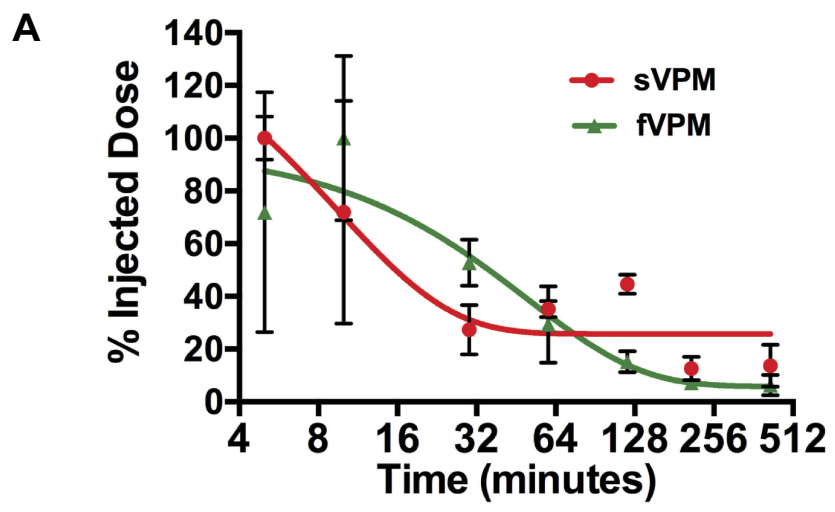

B

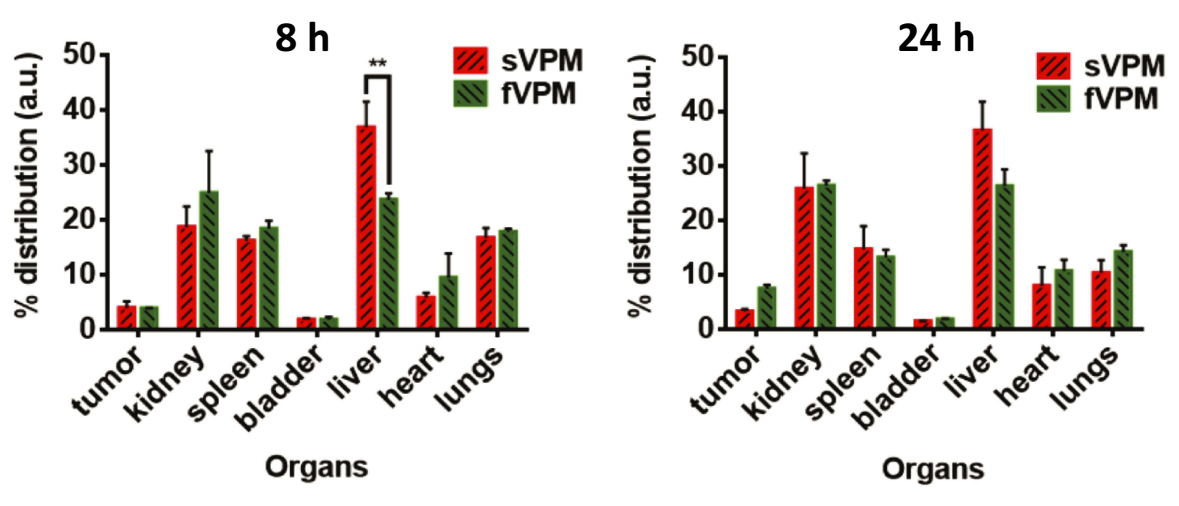

C

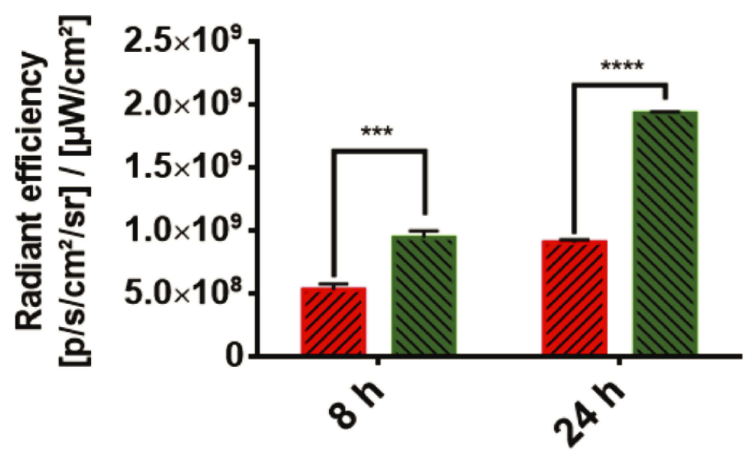

D

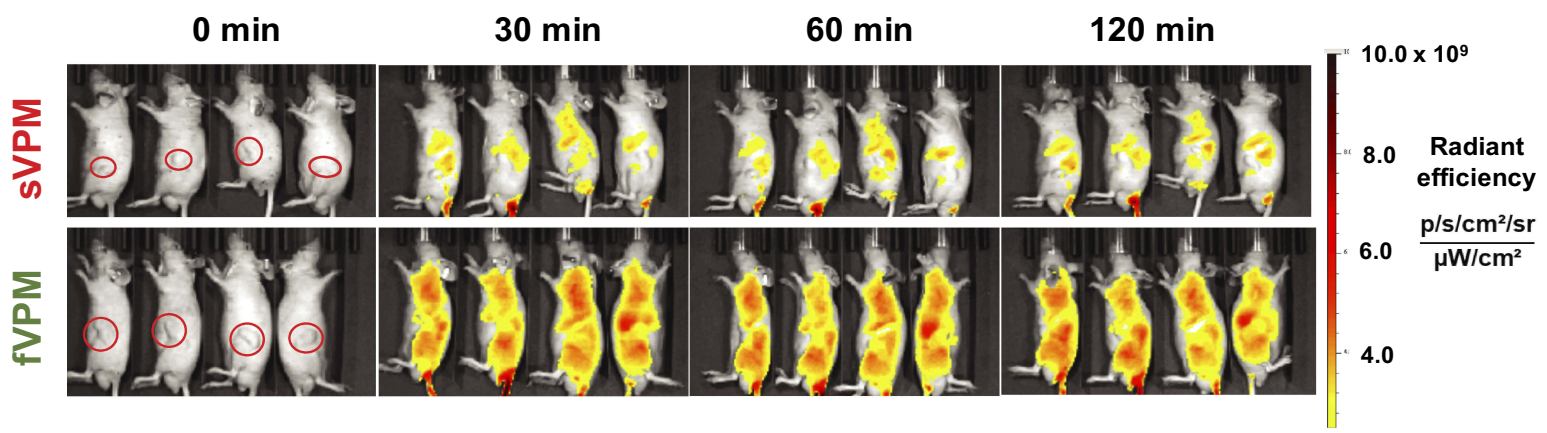

Figure 4 fVPM exhibit enhanced pharmacokinetic properties compared to sVPM in an ectopic human GBM tumor mouse flank model. (A) sVPM and fVPM in blood at 5, 10 , 30, 60, 120, 210, and 420 min timepoints, (B) 8 hrs and 24 hrs biodistribution for tumors and major organs ( $n=2$, mean \pm SD, one-way ANOVA with Bonferroni's multiple comparisons test (**p $\leq 0.01)$ ). (C) Nanoparticle signal in tumors after 8 and $24 \mathrm{hrs}(\mathrm{n}=2$, mean \pm SD, one-way ANOVA with Bonferroni's multiple comparisons test $(* * * \mathrm{p} \leq$ $0.00 \mathrm{I}$, ***** $\leq 0.000 \mathrm{I}$ )). (D) sVPM and fVPM- treated animals under IVIS after $0 \mathrm{~min}, 30 \mathrm{mins}, 60 \mathrm{mins}$, and I 20 mins. Animals in the same image are replicates. Red circles in leftmost panels indicate the location of tumors. 
counterpart, both fVPM and sVPM were systemically injected in mice with GBM tumors in the flank. Blood samples were taken over the course of $7 \mathrm{hrs}$ to evaluate the clearance of micelles. Figure 4A shows that fVPM were cleared more slowly than sVPM. fVPM had a half-life of approximately 35 mins, whereas the half-life of sVPM was calculated to be approximately 6.6 mins. A longer blood circulation will increase the likelihood of the micelles to enter the tumor microenvironment via leaky vasculature following repeated flow-through in systemic circulation.

To determine the localization of SVPM and FVPM to the tumor, NIR dye-loaded micelles were injected via the tail vein. The animals were sacrificed after 8 and $24 \mathrm{hrs}$, and their organs were harvested and read under IVIS to measure emitted signal. Figure 4B shows that the percent biodistribution in the tumors after $8 \mathrm{hrs}$ was $3.92 \%$ and $3.91 \%$ for sVPM and fVPM, respectively. After $24 \mathrm{hrs}$, the biodistribution in the tumors was $3.26 \%$ and $7.43 \%$ for sVPM and fVPM, respectively. Although not a statistically significant difference, the more than double tumor accumulation for fVPM is promising. While comparable tumor accumulation was observed between both micelles after $8 \mathrm{hrs}$, there was significantly more accumulation in the liver from sVPM compared to fVPM ( $\mathrm{p} \leq$ 0.01 ), suggesting that there may be a lower clearance likelihood of the fVPM compared to SVPM in circulation. Signal from the micelles in the tumors (Figure 4C) shows that there was a statistically significant difference in absolute tumor signal between mice treated with SVPM and fVPM. After 8 hrs, the radiant efficiencies in the tumors were $5.28 \times 10^{8}$ and $9.43 \times 10^{8}\left(\mathrm{p} / \mathrm{s} / \mathrm{cm}^{2} / \mathrm{sr}\right) /\left(\mu \mathrm{W} / \mathrm{cm}^{2}\right)$ for sVPM and fVPM-treated mice ( $\sim 1.8$-fold difference), respectively $(\mathrm{p} \leq 0.001)$. After 24 hrs, the radiant efficiencies in the tumors were $9.06 \times 10^{8}$ and $1.93 \times 10^{9}\left(\mathrm{p} / \mathrm{s} / \mathrm{cm}^{2} / \mathrm{sr}\right) /\left(\mu \mathrm{W} / \mathrm{cm}^{2}\right)$, for sVPM and fVPMtreated mice $(\sim 2.1$-fold difference), respectively $(\mathrm{p} \leq 0.0001)$. As depicted in Figure S4A and $\underline{B}$, significant differences in micelle accumulation normalized to organ mass were measured only in the spleen at $24 \mathrm{hrs}$.

Based on these in vivo results, the engineered filamentous micelle morphology was observed to provide longer circulation time and partial avoidance of critical clearance mechanisms. Figure 4D highlights this sharp difference with IVIS images of the treated animals. To further improve tumor accumulation, an active targeting moiety, such as hyaluronic acid or folic acid, could be incorporated into the micelle design to target receptors overexpressed on GBM cells (ie CD44 and folate, respectively). ${ }^{48,49}$ These ligands can be conjugated to the micelle surface in efforts to improve the chemotherapeutic impact and translational potential of these micelles.
Furthermore, while the ectopic subcutaneous tumor model used in this work does not fully recapitulate all of the characteristics of an orthotopic model such as the surrounding brain parenchyma and blood-brain barrier (BBB), it does allow for investigation and analysis of the pharmacokinetics and biodistribution of differently shaped micelles in an in vivo tumor model.

\section{Conclusion}

This study investigated engineered verteporfin (VP)-loaded spherical and filamentous micelles for use as a safe therapy for GBM. By following thermodynamic principles of selfassembly, we engineered triblock copolymers accordingly to generate specifically shaped structures. ${ }^{37}$ As anticipated, a more hydrophobic backbone in combination with a smaller PEG molecular weight yielded a high aspect ratio, wormlike morphology. For spherical and filamentous micelles encapsulating VP, significantly lower VP uptake and induced cytotoxicity was found in healthy human astrocytes (NHA) compared to GBM cells. In addition, an ectopic mouse xenograft tumor model was utilized for comparing pharmacokinetics and biodistribution of spherical and filamentous micelles. Filamentous micelles had a half-life of approximately 35 mins in comparison to the 6.6 min half-life of the spherical micelles. fVPM tumor accumulation was significantly greater at both $8 \mathrm{hrs}$ ( 1.8-fold greater) and $24 \mathrm{hrs}$ ( 2.1-fold greater) compared to sVPM. The filamentous micelle system demonstrates an ability to circumvent systemic barriers that limit nanoparticle-mediated delivery. Collectively, this work demonstrates the beneficial therapeutic properties of VP-based filamentous micelles for the management and treatment of GBMs with the potential to extend patient survival and quality of life.

\section{Acknowledgments}

The authors thank Drs J. Laterra and A. Vescovi for access to GBM1A cells. The authors thank the NIH for support (R01CA228133，R43CA221490，R01CA200399，R01EB 016721, R01CA183827, R01CA195503, R01CA216855).

\section{Disclosure}

A.Q.H. was supported by the Mayo Clinic Professorship and a Clinician Investigator award. J.J.G. was supported by the Bloomberg $\sim$ Kimmel Institute for Cancer Immunotherapy. J.K. received fellowship support from Samsung Scholarship. The authors report no other conflicts of interest in this work. 


\section{References}

1. Davis ME. Glioblastoma: overview of disease and treatment. Clin J Oncol Nurs. 2016;20(5 Suppl):S2-S8.

2. Stupp R, Mason WP, van den Bent MJ, et al. Radiotherapy plus concomitant and adjuvant temozolomide for glioblastoma. $N$ Engl J Med. 2005;352(10):987-996. doi:10.1056/NEJMoa043330

3. Tamimi A, Juweid M. Epidemiology and Outcome of Glioblastoma. Brisbane (AU): Codon Publications; 2017.

4. Hochberg FH, Pruitt A. Assumptions in the radiotherapy of glioblastoma. Neurology. 1980;30(9):907-911. doi:10.1212/WNL.30.9.907

5. Wen PY, Kesari S. Malignant gliomas in adults. $N$ Engl $J$ Med. 2008;359(5):492-507. doi:10.1056/NEJMra0708126

6. Daneman R, Prat A. The blood-brain barrier. Cold Spring Harb Perspect Biol. 2015;7(1):a020412. doi:10.1101/cshperspect.a020412

7. Wei S, Wang J, Oyinlade O, et al. Heterozygous IDH1(R132H/WT) created by "single base editing" inhibits human astroglial cell growth by downregulating YAP. Oncogene. 2018;37(38):5160-5174. doi:10.1038/ s41388-018-0334-9

8. Shah SR, Quinones-Hinojosa A, Xia S. Advances in brain cancer: creating monoallelic single point mutation in IDH1 by single base editing. J Oncol Res Ther. 2019;5(5):166.

9. Xiao W, Sohrabi A, Seidlits SK. Integrating the glioblastoma microenvironment into engineered experimental models. Future Sci OA. 2017;3(3):Fso189. doi:10.4155/fsoa-2016-0094

10. Shah SR, Tippens ND, Park J, et al. YAP controls cell migration and invasion through a Rho-GTPase switch. bioRxiv. 2019;602052.

11. Park J, Kim D-H, Shah SR, et al. Switch-like enhancement of epithelial-mesenchymal transition by YAP through feedback regulation of WT1 and Rho-family GTPases. Nat Commun. 2019;10 (1):2797. doi:10.1038/s41467-019-10729-5

12. Shah SR, David JM, Tippens ND, et al. Brachyury-YAP regulatory axis drives stemness and growth in cancer. Cell Rep. 2017;21 (2):495-507. doi:10.1016/j.celrep.2017.09.057

13. Noch EK, Ramakrishna R, Magge R. Challenges in the treatment of glioblastoma: multisystem mechanisms of therapeutic resistance. World Neurosurg. 2018;116:505-517. doi:10.1016/j.wneu.2018.04.022

14. Jiapaer S, Furuta T, Tanaka S, Kitabayashi T, Nakada M. Potential strategies overcoming the temozolomide resistance for glioblastoma. Neurol Med Chir (Tokyo). 2018;58(10):405-421. doi:10.2176/nmc.ra.2018-0141

15. Karlsson J, Vaughan HJ, Green JJ. Biodegradable polymeric nanoparticles for therapeutic cancer treatments. Annu Rev Chem Biomol Eng. 2018;9:105-127. doi:10.1146/annurev-chembioeng-060817-084055

16. Singh R, Lillard JW Jr. Nanoparticle-based targeted drug delivery. Exp Mol Pathol. 2009;86(3):215-223. doi:10.1016/j.yexmp.2008.12.004

17. Martinez Rivas CJ, Tarhini M, Badri W, et al. Nanoprecipitation process: from encapsulation to drug delivery. Int $J$ Pharm. 2017;532(1):66-81. doi:10.1016/j.ijpharm.2017.08.064

18. Barua S, Yoo JW, Kolhar P, Wakankar A, Gokarn YR, Mitragotri S. Particle shape enhances specificity of antibody-displaying nanoparticles. Proc Natl Acad Sci U S A. 2013;110(9):3270-3275. doi:10.1073/ pnas. 1216893110

19. Meyer RA, Mathew MP, Ben-Akiva E, et al. Anisotropic biodegradable lipid coated particles for spatially dynamic protein presentation. Acta Biomater. 2018;72:228-238. doi:10.1016/j.actbio.2018.03.056

20. Kalaydina RV, Bajwa K, Qorri B, Decarlo A, Szewczuk MR. Recent advances in "smart" delivery systems for extended drug release in cancer therapy. Int $J$ Nanomedicine. 2018;13:4727-4745. doi:10.2147/IJN. S168053

21. Shah SR, Kim J, Schiapparelli P, et al. Verteporfin-loaded polymeric microparticles for intratumoral treatment of brain cancer. Mol Pharm 2019;16(4):1433-1443. doi:10.1021/acs.molpharmaceut.8b00959

22. Scott LJ, Goa KL. Verteporfin. Drugs Aging. 2000;16(2):139-146; discussion 147-138. doi:10.2165/00002512-200016020-00005

23. Youssef PN, Sheibani N, Albert DM. Retinal light toxicity. Eye (Lond). 2011;25(1):1-14. doi:10.1038/eye.2010.149
24. Liu-Chittenden Y, Huang B, Shim JS, et al. Genetic and pharmacological disruption of the TEAD-YAP complex suppresses the oncogenic activity of YAP. Genes Dev. 2012;26(12):1300-1305. doi:10.1101/gad. 192856.112

25. Zanconato F, Cordenonsi M, Piccolo S. YAP/TAZ at the roots of cancer. Cancer Cell. 2016;29(6):783-803. doi:10.1016/j.ccell.2016.05.005

26. Lin C, Hu Z, Lei B, et al. Overexpression of Yes-associated protein and its association with clinicopathological features of hepatocellular carcinoma: a meta-analysis. Liver Transpl. 2017;37(11):1675-1681. doi:10.1111/liv.2017.37.issue-11

27. Shah SR, Tippens N, Park J, et al. 217 YAP is ready to rac and rho: elucidation of a novel YAP-driven network that potentiates brain cancer cell dispersal and confers poor survival in patients. Neurosurgery. 2016;63 (CN_suppl_1):185. doi:10.1227/01.neu.0000489786.22041.2d

28. Wei H, Wang F, Wang Y, et al. Verteporfin suppresses cell survival, angiogenesis and vasculogenic mimicry of pancreatic ductal adenocarcinoma via disrupting the YAP-TEAD complex. Cancer Sci. 2017;108(3):478-487. doi:10.1111/cas.13138

29. Huggett MT, Jermyn M, Gillams A, et al. Phase I/II study of verteporfin photodynamic therapy in locally advanced pancreatic cancer. Br J Cancer. 2014;110(7):1698-1704. doi:10.1038/bjc.2014.95

30. Kim J, Shamul JG, Shah SR, et al. Verteporfin-loaded poly(ethylene glycol)-poly(beta-amino ester)-poly(ethylene glycol) triblock micelles for cancer therapy. Biomacromolecules. 2018;19(8):3361-3370. doi:10.1021/acs.biomac. 8 b00640

31. Martinez-Gutierrez JC, Ruiz-Valls A, Shah SR, Riggins GJ, Quinones-Hinojosa A. MNGO-08: meningioma growth inhibition and radiosensitization by the small molecule yap inhibitor verteporfin. Neuro Oncol. 2015;17(Suppl 5):v131-v131. doi:10. 1093/neuonc/nov220.08

32. Green JJ, Langer R, Anderson DG. A combinatorial polymer library approach yields insight into nonviral gene delivery. Acc Chem Res. 2008;41(6):749-759. doi:10.1021/ar7002336

33. Sunshine JC, Peng DY, Green JJ. Uptake and transfection with polymeric nanoparticles are dependent on polymer end-group structure, but largely independent of nanoparticle physical and chemical properties. Mol Pharm. 2012;9(11):3375-3383. doi:10.1021/mp3004176

34. Kim J, Kang Y, Tzeng SY, Green JJ. Synthesis and application of poly (ethylene glycol)-co-poly(beta-amino ester) copolymers for small cell lung cancer gene therapy. Acta Biomater. 2016;41:293-301. doi:10.1016/j.actbio.2016.05.040

35. Galli R, Binda E, Orfanelli U, et al. Isolation and characterization of tumorigenic, stem-like neural precursors from human glioblastoma. Cancer Res. 2004;64(19):7011-7021. doi:10.1158/0008-5472.CAN04-1364

36. Tzeng SY, Wilson DR, Hansen SK, Quinones-Hinojosa A, Green JJ. Polymeric nanoparticle-based delivery of TRAIL DNA for cancer-specific killing. Bioeng Transl Med. 2016;1(2):149-159. doi: $10.1002 / \mathrm{btm} 2.10019$

37. Israelachvili J. The science and applications of emulsions - an overview. Colloids Surf a Physicochem Eng Asp. 1994;91:1-8. doi:10.1016/0927-7757(94)02743-9

38. Tzeng SY, Green JJ. Subtle changes to polymer structure and degradation mechanism enable highly effective nanoparticles for siRNA and DNA delivery to human brain cancer. Adv Healthc Mater. 2013;2 (3):468-480. doi:10.1002/adhm.v2.3

39. Qiu L, Xu C-R, Zhong F, Hong C-Y, Pan C-Y. Fabrication of functional nano-objects through raft dispersion polymerization and influences of morphology on drug delivery. ACS Appl Mater Interfaces. 2016;8(28):18347-18359. doi:10.1021/acsami.6b04693

40. Park JH, von Maltzahn G, Zhang L, et al. Systematic surface engineering of magnetic nanoworms for in vivo tumor targeting. Small. 2009;5(6):694-700. doi:10.1002/smll.200801789

41. Park JH, von Maltzahn G, Zhang L, et al. Magnetic iron oxide nanoworms for tumor targeting and imaging. Adv Mater. 2008;20 (9):1630-1635. doi:10.1002/adma.200800004 
42. Toy R, Peiris PM, Ghaghada KB, Karathanasis E. Shaping cancer nanomedicine: the effect of particle shape on the in vivo journey of nanoparticles. Nanomedicine (Lond). 2014;9(1):121-134. doi:10.2217/ nnm.13.191

43. Meng F, Engbers GH, Feijen J. Polyethylene glycol-grafted polystyrene particles. J Biomed Mater Res A. 2004;70(1):49-58. doi:10.1002/ jbm.a.30056

44. Wang X, Hu X, Li J, et al. Influence of cell size on cellular uptake of gold nanoparticles. Biomater Sci. 2016;4(6):970-978. doi:10.1039/ C6BM00171H

45. Farvadi F, Ghahremani MH, Hashemi F, et al. Cell shape affects nanoparticle uptake and toxicity: an overlooked factor at the nanobio interfaces. J Colloid Interface Sci. 2018;531:245-252. doi:10.1016/j. jcis.2018.07.013

46. Hatoum A, Mohammed R, Zakieh O. The unique invasiveness of glioblastoma and possible drug targets on extracellular matrix. Cancer Manag Res. 2019;11:1843-1855. doi:10.2147/CMAR. $\mathrm{S} 186142$
47. Brandao M, Simon T, Critchley G, Giamas G. Astrocytes, the rising stars of the glioblastoma microenvironment. Glia. 2019;67(5):779-790. doi:10.1002/glia.v67.5

48. Merzak A, Koocheckpour S, Pilkington GJ. CD44 mediates human glioma cell adhesion and invasion in vitro. Cancer Res. 1994;54 (15):3988-3992.

49. Nam L, Coll C, Erthal LCS, et al. Drug delivery nanosystems for the localized treatment of glioblastoma multiforme. Materials. 2018;11 (5):779. doi:10.3390/ma11050779

\section{Publish your work in this journal}

The International Journal of Nanomedicine is an international, peerreviewed journal focusing on the application of nanotechnology in diagnostics, therapeutics, and drug delivery systems throughout the biomedical field. This journal is indexed on PubMed Central, MedLine, CAS, SciSearch ${ }^{\mathbb{R}}$, Current Contents ${ }^{\mathbb{R}} /$ Clinical Medicine, $^{-}$
Journal Citation Reports/Science Edition, EMBase, Scopus and the Elsevier Bibliographic databases. The manuscript management system is completely online and includes a very quick and fair peer-review system, which is all easy to use. Visit http://www.dovepress.com/ testimonials.php to read real quotes from published authors. 